\title{
Using assessment data to improve equity: How teachers use insights from the Scottish National Standardised Assessments
}

\author{
Dr Sarah Richardson \\ Australian Council for Educational Research \\ Dr Sladana Krstic \\ Australian Council for Educational Research \\ https://doi.org/10.37517/978-1-74286-638-3_10
}

\begin{abstract}
Dr Sarah Richardson is a passionate researcher, educator and writer. She has been working in the education sector for 28 years as a teacher, lecturer, researcher and research director. Sarah is the Research Director of the Surveys and International Assessments team in the Australian Council for Educational Research. She returned to Australia in April 2021 having been Deputy CEO and Research Director of ACER UK, and previously Research Director of ACER India. Sarah has a PhD in education and politics from the University of Melbourne, a Master's Degree in International Relations from the University of Amsterdam and a Bachelor's Degree in Human Geography from the University of Liverpool.
\end{abstract}

Dr Sladana Krstic leads the psychometrics and research team for ACER UK. She has worked on a variety of projects, including the Scottish National Standardised Assessments; the British Council's English Impact project; the International Baccalaureate programmes; and the Royal Society of Chemistry evaluation programme. Sladana has a Doctorate in Education and is an expert researcher in quantitative and qualitative methodology, data analysis, sampling designs, and questionnaire development. She is currently engaged in a ground-breaking research project for the International Baccalaureate Organisation and the Jacobs Foundation on curiosity, creativity and learning.

\section{Abstract}

Evidence-based decision-making is regarded as an important indicator of quality in schools around the world. Using data gathered from assessments, in conjunction with other insights, can help school leaders and teachers better meet the needs of learners. In schools that cater to disadvantaged learners, using data to design targeted interventions plays an important role in improving equity. In this paper we report on a study with five schools in Scotland. All schools had learner cohorts characterised by multiple layers of disadvantage. Informed by the theoretical underpinnings of sensemaking theory, we investigated how teachers and school leaders used data from the Scottish National Standardised Assessments (SNSA). Our findings suggest that teachers and leaders are adept at combining assessment data with other insights - including their own observations. All schools were active in using data to inform decision-making, both at the whole-school level and at the classroom level. They reported multiple uses of data, from validating their own instincts to targeting support to particular cohorts of learners. We suggest that the way in which SNSA is designed - explicitly providing data to teachers to help inform their professional judgement - is a factor in the positive approach to data usage among these schools.

\section{Introduction}

There is a growing focus on the importance of evidence-based approaches to inform educational decision-making. Large-scale assessment is a key component of this, with the intent that it provides educational professionals with empirical insights that they can use to inform strategies that improve learning. 
Unfortunately, research shows that many teachers struggle to apply data to their teaching practice (Cowie \& Cooper, 2017; Selwyn, 2016) and that school leaders are unsure of how to support good data practices at their schools (Young et al., 2018). Overall, this tends to lead to a 'sorry mixture of confusion, technical naivety and misleading advice' (Demie, 2010, p. 446), resulting in some studies suggesting that many schools do not use data-based decisions (Silva et al., 2020).

In this study, we investigated how teachers and school leaders in Scottish schools use data to inform strategies to support improved student learning. This research was undertaken in a context in which the Scottish National Standardised Assessments (SNSA) were designed with a specific focus on providing teachers with detailed information about student learning, and support in applying this information to their professional practice. Our focus was on schools that catered to some of the most disadvantaged learners in Scotland.

\section{Background and context}

The Scottish Government's Curriculum for Excellence has established a new vision for education for Scottish learners (Education Scotland, 2020). One of its strategies is to deliver 'excellence and equity for learners'. Developed in 2017 within this framework, the SNSAs are a unique approach to large scale assessment, designed specifically to provide 'diagnostic information to support teachers' professional judgement' (Scottish Government, 2017).

The SNSAs are online, adaptive assessments for learners in Grades 1, 4, 7 and 10 of all government primary and secondary schools in Scotland and focus on numeracy, reading and writing. Teachers receive immediate diagnostic reports on individual learners and groups of learners and the goal is that they will 'assess children's progress and plan next steps in learning' (Scottish Government, 2017). Teachers are able to choose when to conduct the assessments, how to conduct them and what to do with the data they receive.

Teachers are offered training on how to implement the SNSA and what to do with the data. Using these data, teachers can identify precisely what their students (both as individuals and as a cohort) know and can do at the time of assessment, with content-specific descriptions providing rich insights into areas of strength and weakness.

The context in which the SNSAs are taking place is one of significant disadvantage. Scotland has a weaker performing education system in comparison with many European countries. In PISA 2018 (Programme for International Student Assessment), for example, Scottish secondary students scored just above the OECD average for reading, a significant drop since 2000 and 2009 (Scottish Government, 2019a). At the primary level, Scottish primary school students' reading levels were below that of many other European countries for reading in 2006 (and lower than the Scottish scores for reading in 2001) (Mullis et al., 2007) and their mathematics levels were below the mean overall Trends in International Mathematics and Science Study (TIMSS) score in 2007 (Mullis et al., 2008).

Educational underachievement is partly explained by the fact that almost a quarter of all children in Scotland live in poverty (Scottish Government, 2019b). In this context, many students have multiple layers of disadvantage (Kintrea, 2018). This means that teachers have challenging terrain to navigate in meeting the needs of students in their classes. With this background in mind, the ability to receive detailed diagnostic information on their students should enable teachers and schools to provide individual students with tailored interventions that meet their specific needs.

The question, however, is whether teachers and school leaders have the skills to use data from the SNSA to target educational interventions that address education inequity. In undertaking our research, we were informed by the conceptual framework of sensemaking theory, which focuses on the ways that individuals try to transform sources of information into a comprehensible interpretation that drives action (Weick et al., 2005). The concept has been applied in a number of 
contexts, including education. The use of data by teachers involves the making of meaning and the development of interpretations that can guide their work. (Riehl et al., 2018; Snodgrass Rangel et al., 2019; Vanlommel \& Schildkamp, 2019).

\section{Methodology}

Our approach was to identify two of the most disadvantaged regions of Scotland (Glasgow and Renfrewshire) and to contact the relevant local government authority to gain permission to undertake research in schools. A total of five schools agreed to participate. To provide context for the findings, a summary of salient characteristics from each school is provided in Table 1. All numbers and percentage estimates were provided by the schools themselves.

Table 1 School characteristics

\begin{tabular}{|l|l|c|c|c|c|}
\hline \multirow{2}{*}{ School } & Level & $\begin{array}{c}\text { Number } \\
\text { of learners }\end{array}$ & $\begin{array}{c}\text { Learners from } \\
\text { SIMD 1-2 } \\
(\%)\end{array}$ & $\begin{array}{c}\text { Learners } \\
\text { with EAL }\end{array}$ & $\begin{array}{c}\text { Learners } \\
\text { with ASN }\end{array}$ \\
\hline A & Primary & 530 & $40-50$ \\
\hline B & Primary & 336 & $50-60$ & $20-30$ & $20-30$ \\
\hline C & Primary & 268 & $40-50$ & $0-20$ & $30-40$ \\
\hline D & Primary & 450 & $10-20$ & $0-10$ & $20-30$ \\
\hline E & Secondary & 1345 & $10-20$ & $0-10$ & $20-30$ \\
\hline
\end{tabular}

1 The first or second vigintile in the Scottish Index of Multiple Deprivation (SIMD)

2 English as an additional language

3 additional support needs

Once agreement was reached, two researchers (at least one of whom was a former teacher) spent one whole day in each school. They conducted semi-structured interviews with between one and three teachers at each school, in addition to a total of nine principal teachers, five head-teachers and nine deputy head-teachers across all schools. The teachers had an average of 16 years of teaching experience. The semi-structured interviews were based on a protocol that was sufficiently consistent to collect similar insights from all schools, while being flexible enough to engage in deep and naturalistic conversations with participants and to respond to the directions that discussions took.

All interviews were audio-recorded and the recordings were transcribed and then coded. The coding approach was informed by grounded theory (Glaser, 1978). The aim was to generate a descriptive and explanatory theory within the conceptual frame of sensemaking theory that can be used to derive practical implications for educational policy and practice.

\section{Findings}

Findings from the data yielded a large number of important insights. Most importantly, they highlighted the large number of ways in which teachers and school leaders were drawing on data: to monitor and track progress; to identify gaps and validate teacher judgements; to plan interventions and tailor teaching; to set expectations; and, to communicate outcomes with stakeholders. School leaders and teachers further provided evidence of the triangulation of data - drawing on a mixture of assessment data and other insights to inform decision-making. 
All schools were found to have an active culture of using data to identify learner achievement. Most schools held regular attainment meetings between leaders and teachers in addition to meetings between the senior management team to utilise data in school planning. Within-school activities were reinforced by a data culture outside of schools, with head teachers attending peer-review meetings with other head teachers in the same local authority each term. In these meetings, attainment data were compared to peer schools in the local area and were also gathered by local authorities to use for benchmarking purposes.

Teachers described using a wide range of assessment types to facilitate triangulation including: classroom-based assessments and direct observations, formative and summative assessments, standardised and diagnostic assessments, such as SNSA, Progress in Reading Assessment (PiRA), teacher and parent questionnaires, and previous teacher reports and observations. Teachers also referred to the use of learner-centric sources of information aimed at capturing the learner's voice and experience, which one termed 'learning conversations with children'. As one teacher commented, 'data is brilliant but it's not good unless you have that voice that goes along with it'.

In terms of data used, all teachers interviewed expressed caution about the risk of over-burdening learners with assessment. Nevertheless, teachers also highlighted the value of accurate assessment data. One reported approach was to emphasise to learners that the assessment was for the teacher as well. Teachers reported that this encouraged learners to be honest and open in sharing the difficulties they were having. Teachers also reported explaining to their classes:

We've done this learning from August to September, I want to make sure that you're all really confident so that I know where to go when we are moving on ... you're doing this to inform me of where we go next - do we need to revise - ... or can we power through?

Interestingly, moderation within and between schools, as well as peer-to-peer observations were also utilised as methods to 'draw a comprehensive picture' of the learner and ensure the quality of the conclusions in terms of the learner's learning. One school also used this as an opportunity to encourage teachers to participate in professional enquiry, including professional reading and research. While interviewees agreed they were 'data rich' in their schools, with multiple sources of data available, they were also cognisant of the impact of over-assessing learners and collecting data for its own sake. As one teacher commented: 'More [data] is not necessarily better data'.

While data from formal assessments were used in all schools, many teachers reported using different assessment methods to supplement formal data, such as a wide range of formative assessment methods that enabled them to adjust lessons as they were progressing, and to plan for subsequent ones. As one teacher reported:

I use formative assessment all the time. I just pick children [to answer questions], and that gives me a good idea who's picking up the lesson, who's understanding what I am saying, and just through the talking and listening I can get that ... [I ask for] thumbs up, thumbs down to show understanding of what I'm saying.

In addition to the variety of data used, teachers also reported using data for a number of different purposes. Interviewees noted using data for planning whole-school, year group, and class level activities. As a teacher explained:

What we were looking to do was to identify those children who were just below average, to see if we could push them on, so that we could target our support around about that group.

In informing the design of interventions, interviewees reported using a range of sources of data, such as about learners' home lives, and combining these with assessment data, records of previous interventions and records from external agencies in order to target support holistically. As a head teacher noted, they try to identify: 
Who's not on track, why they're not on track, is it something to do with something that's happening with the families? Is it social work being involved? We look at all the interventions surrounding that one child, what's impacting on their success and their achievement and then we see what we can put in place for them.

In the same ways that schools reported using data to help learners who needed greater support, some also reported using this approach to group high-achieving learners. As one interviewee described:

... we've got a challenge group set up because they were, you know, heads above the other wee ones with regard to understanding and their comprehension, so there's a wee challenge group that we've set up for that.

In addition to using data for planning purposes, teachers reported using assessment results to tailor their teaching approaches. Interviewees also reported using assessment data to monitor learners' performance and progression, and to identify any gaps that needed to be addressed with targeted interventions. These quotes reflect some of the uses of data:

The teacher can use [data] to track and ensure that a child is still making positive progress and ensure there are appropriate targets being set for the children.

We look at the attainment across the school, and we look at any gaps that there are. And try to come up with, as a team, why we think there are these gaps and what we are going to do about it.

Finally, and perhaps most importantly, teachers reported using assessment data to validate their own professional judgement, question anomalies and to work together with colleagues to examine data patterns and learn from one another. Two quotes illustrate these themes:

As a teacher you always want to be assured that what you're doing is the right thing, and what you have thought is the right thing. I think it certainly does give peace of mind that our standards and expectations, the criteria for a certain level, is accurate.

I mean obviously teacher judgement is - trumps everything - but we do find that all the data informs it really, really quite well.

\section{Conclusion}

This study drew on insights from teachers and school leaders about the ways in which empirical data from the SNSA, in conjunction with other information, supported their professional practice. In the schools involved in this study, data were used for multiple purposes and at multiple junctures throughout the school year. Ultimately, it is through the process of triangulation: using multiple sources of data, in conjunction with observations and knowledge of learners, that the most accurate judgements are achieved. The study indicates that having a holistic approach, in which assessment data is used as one indicator of learner ability but is not the sole determinant of it, is the most meaningful way to inform interventions and classroom practices.

In Scotland, the SNSA is a key assessment helping teachers understand the progress of each child, which informs planning for everyone, from teachers to the senior management team at each school. The supportive nature of SNSA - in which data are explicitly provided to teachers to help inform their professional judgement - is likely to be a factor in the positive approach to data usage. This is in contrast to many large-scale assessment programmes where data are used for accountability purposes, taking the element of judgement away from teachers and the profession (Lingard et al., 2017). 
In all schools in this study, the use of empirical insights was not the responsibility of individual teachers in isolation, but a whole-of-school responsibility. This helps to foster teacher capacity and beliefs about data (Datnow \& Hubbard, 2016) and promotes collective efficacy, perceived control and motivation (Prenger \& Schildkamp, 2018). In a supportive environment, teachers are confident in making inferences that start from the question 'what do the data tell me?' (Coburn et al., 2009). In this way, making sense of data contributes to continuous improvement strategies to inform teaching and learning, something that can be considered a 'strategic sensemaking endeavour' (Park et al., 2012, p. 667).

\section{References}

Coburn, C., Honig, M. \& Stein, M. (2009). What is the evidence on districts' use of evidence? In J. D. Bransford, D. J. Stipek, N. H. Vye, L. M. Gomez, \& D. Lam (Eds.) The role of research in educational improvement (pp. 67-86). Harvard Educational Press.

Cowie, B., \& Cooper, B. (2017). Exploring the challenge of developing student teacher data literacy. Assessment in Education: Principles, Policy \& Practice, 24(2): 147-163. https://doi.org/10.1080/096 9594X.2016.1225668

Datnow, A. \& Hubbard, L. (2016). Teacher capacity for and beliefs about data-driven decision-making: A literature review of international research. Journal of Educational Change, 17:7-28. https://doi. org/10.1007/s10833-015-9264-2

Demie, F. (2010). Using value-added data for school self-evaluation: A case study of practice in innercity schools. School Leadership and Management, 23(4), 445-467. https://doi.org/10.1080/136324 3032000150971

Education Scotland (2020). What is Curriculum for Excellence? https://education.gov.scot/educationscotland/scottish-education-system/policy-for-scottish-education/policy-drivers/cfe-buildingfrom-the-statement-appendix-incl-btc1-5/what-is-curriculum-for-excellence \#

Glaser, B. (1978). Theoretical sensitivity: Advances in the methodology of grounded theory. Sociology Press.

Kintrea, K. (2018). Education, disadvantage and place in Scottish secondary education, CR\&DALL Working Paper CR\&DALL WP301/2018, CR\&DALL, Glasgow (UK).

Lingard, B., Sellar, S., \& Lewis, S. (2017). Accountabilities in schools and school systems. Oxford research encyclopaedia of education. https://oxfordre.com/education/view/10.1093/ acrefore/9780190264093.001.0001/acrefore-9780190264093-e-74.

Mullis, I., Martin, M., Kennedy, A. and Foy, P. (2007). PIRLS 2006 international report. TIMSS \& PIRLS International Study Centre.

Mullis, I., Martin, M. and Foy, P. (2008). TIMSS 2007 international mathematics report. TIMSS \& PIRLS International Study Centre.

Park, V., Daly, A. \& Wishard Guerra, A. (2012). Strategic framing: How leaders craft the meaning of data use for equity and learning. Educational Policy, 27(4), 645-675. https://doi. org/10.1177/0895904811429295

Prenger, R., \& Schildkamp, K. (2018). Data-based decision-making for teacher and student learning: A psychological perspective on the role of the teacher. Educational Psychology, 38(6), 734-752. https://doi.org/10.1080/01443410.2018.1426834 
Riehl, C., Earle, H., Nagarajan, P, Schwitzman, T. \& Vernikoff, L. (2018). Following the path of greatest persistence: Sensemaking, data use and the everyday practice of teaching. In N. Barnes \& H. Fives (Eds). Cases of teachers data use. Routledge.

Scottish Government (2019a). Programme for International Student Assessment (PISA) 2018 : Highlights from Scotland's results. https://www.gov.scot/publications/programme-internationalstudent-assessment-pisa-2018-highlights-scotlands-results/pages/5/

Scottish Government (2019b). Poverty and income inequality in Scotland: 2015-2018. https://www. gov.scot/publications/poverty-income-inequality-scotland-2015-18/pages/4/

Scottish Government (2017). Scottish National Standardised Assessments. https:// standardisedassessment.gov.scot/

Selwyn, N. (2016). 'There's so much data': Exploring the realities of data-based school governance. European Educational Research Journal, 15(1), 54-68. https://doi.org/10.1177/1474904115602909

Snodgrass Rangel, V., Bell, E. \& Monroy, C. (2019). Teachers' sensemaking and data use: Implementation in science classrooms. Education and Urban Society, 51(4), 526-554. https://doi. org/10.1177/0013124517727053

Silva, M., Collier-Meek, M., Codding, R., Kleinert, W. \& Feinberg, A. (2020). Data collection and analysis in response-to-intervention: A survey of school psychologists. Contemporary School Psychology. https://doi.org/10.1007/s40688-020-00280-2

Vanlommel, K. \& Schildkamp, K. (2019). How do teachers make sense of data in the context of highstakes decision-making? American Educational Research Journal, 56(3), 792-821. https://doi. org/10.3102/0002831218803891

Weick, K., Sutcliffe, K. and Obstfeld, D. (2005). Organizing and the process of sensemaking. Organization Science, 16(4), 409-421. https://doi.org/10.1287/orsc.1050.0133

Young, C., McNamara, G., Brown, M. and O-Hara, J. (2018). Adopting and adapting: School leaders in the age of data-informed decision-making. Educational Assessment, Evaluation and Accountability, 30, 133-158. https://doi.org/10.1007/s11092-018-9278-4 